\title{
O Brasil e a Conferência de Washington (1951)
}

\author{
Danilo José DALIO \\ Shiguenoli MIYAMOTO ••
}

\begin{abstract}
Resumo: A década de 1940 representou o auge e o declínio do paradigma das "relações especiais" Brasil - Estados Unidos, predominante por quase meio século na política exterior brasileira. Após a experiência bem sucedida de colaboração durante a segunda guerra mundial, o Brasil enfrentou um período de frustração e desapontamento nas suas relações com o governo de Washington. Emergindo como potência hegemônica, os sucessivos governos norte-americanos constituíram interesses e objetivos globais na nova ordem internacional, pouco restando para o atendimento das demandas dos países latino-americanos. A IV Reunião de Consulta dos Chanceleres Americanos, realizada em Washington, entre março e abril de 1951, explicitou não apenas o dissídio de objetivos e interesses entre os Estados Unidos e os países latino-americanos no pós-guerra, mas também o surgimento de uma nova perspectiva de relacionamento dentro do continente, pautada em negociações realistas e pragmáticas, sobretudo por parte do Brasil.
\end{abstract}

Palavras-chave: Conferência de Washington; Relações Brasil Estados Unidos; Política Externa Brasileira; América Latina.

- Mestrando no Programa de Pós-Graduação em Ciência Política Instituto de Filosofia e Ciências Humanas - UNICAMP. Desenvolve pesquisa sobre "A política externa do segundo governo Vargas para os Estados Unidos (1951-1954)", financiada pela Fundação de Amparo à Pesquisa do Estado de São Paulo (FAPESP) - 13081-970 - Campinas SP - Brasil. E-mail: djdalio@bol.com.br

- Professor Titular do Departamento de Ciência Política - UNICAMP 13081-970 - Campinas - SP - Brasil. E-mail: shiguenoli@gmail.com 


\section{Introdução}

$\mathrm{Na}$ virada dos anos 50, a conjuntura internacional marcada pelo conflito Leste-Oeste obrigou os Estados Unidos, na condição auto-outorgada de guardião do mundo ocidental, a abrir frentes diversas, que tiveram reflexos em seu relacionamento com a América Latina. Em primeiro lugar, elemento fundamental na agenda norte-americana dizia respeito às transformações verificadas no jogo do poder global, após a União Soviética ter detonado o seu primeiro artefato nuclear, em agosto de 1949, enquanto no mesmo ano Mao Zedong saiu vitorioso na revolução chinesa. Em segundo lugar, a Guerra da Coréia despertou na Casa Branca a necessidade de mobilizar o apoio da América Latina para suas incursões no front asiático. Em terceiro lugar, os golpes de Estado que se sucediam em distintas partes do continente latino-americano, sob indefinidas colorações político-ideológicas, converteram-se em motivo de preocupação para o governo de Washington. ${ }^{1}$ No conjunto esses acontecimentos motivaram o enrijecimento da política de containment dos Estados Unidos, ao mesmo tempo em que abriram um canal de negociações para os países situados abaixo do Rio Grande.

Neste contexto, a IV Reunião de Consulta dos Chanceleres Americanos, realizada em Washington entre 26 de março e 7 de abril de 1951, representou a primeira grande oportunidade para que o estado de abandono ao qual a América Latina havia sido relegada no imediato pós-guerra fosse intensamente questionado. Fundamentalmente prevista para tratar de assuntos referentes à preparação e cooperação militares entre os países do continente, a Conferência de Washington desde o início tornou-se um palco de divergências, com perspectivas e objetivos bastante diferenciados entre as demandas dos Estados Unidos e as das nações latino-americanas. Papel importante foi exercido pela delegação brasileira que, praticamente, liderou as reivindicações apresentadas pelos demais parceiros do continente. Os debates mostraram clarente 
o descontentamento da América Latina com os propósitos norteamericanos: enquanto a Casa Branca tinha mais interesse nos aspectos de colaboração militar, os demais países focalizavam suas lentes nas necessidades econômicas da região.

Essa experiência político-diplomática entre Washington e as nações latino-americanas não tiveram apenas um resultado conjuntural. Os reflexos puderam ser sentidos posteriormente, arrastando-se ao longo dos anos, inspirando os debates interamericanos e auxiliando na conduta da política exterior brasileira, após o segundo governo de Getúlio Vargas (19511954).

No limiar dos anos 50, apresentaram-se, portanto, condições propícias para o estabelecimento de relações bastante amistosas entre o Brasil e os Estados Unidos. A política externa brasileira, desde o término da Segunda Guerra Mundial, não conseguia manter o mesmo padrão que orientou seu relacionamento com a Casa Branca durante aquele conflito. Mas recebia agora novo alento, através das oportunidades que se abriam com os ventos favoráveis dessa conjuntura.

A preocupação central desse texto é analisar as características da estratégia adotada pela política exterior do governo Vargas na IV Reunião de Consulta dos Chanceleres Americanos. Com esse intuito, procuraremos apreender a importância e a influência que a atuação brasileira naquele evento teve para a dinâmica da diplomacia nos anos posteriores. $\mathrm{Ou}$ seja, verificar os reflexos na conduta da PEB, com uma possível mudança do paradigma fundamental que a norteava até então. Antes de discutirmos os aspectos principais da Conferência de Washington, destacaremos, ainda que brevemente, as premissas que sustentaram a política exterior brasileira na primeira metade do século XX.

\section{As "relações especiais" Brasil - Estados Unidos: auge e declínio}

Por mais de meio século, a diplomacia brasileira esteve apoiada nas iniciativas e nos princípios construídos pelo 
Chanceler José Maria da Silva Paranhos Júnior, conhecido como Barão do Rio Branco (1902-1912), enquanto responsável maior pela conduta externa do país. À frente da diplomacia por cerca de dez anos, o Barão difundiu um paradigma de comportamento diplomático e de política externa, que privilegiava, sobretudo, estreitos vínculos com os Estados Unidos (BUENO, 2003).

Essa inclinação da diplomacia brasileira por uma aproximação maior com o governo norte-americano tinha seus motivos. De um lado, nos mesmos moldes de Alexis de Tocqueville, à percepção da emergência dos Estados Unidos como futura potência global e, a curto prazo, como nação hegemônica no Hemisfério Ocidental ${ }^{2}$; por outro lado, à concepção de que uma aliança tácita com esse país aumentaria o poder de barganha do Brasil no continente. ${ }^{3}$ Desde então, a política externa repousaria essencialmente sobre três premissas fundamentais, constituindo-se em verdadeiro paradigma, seguido por mais de meio século nas relações internacionais do país (RICUPERO, 1996), a saber:

a) A convergência ideológica: Brasil e Estados Unidos partilhavam os mesmos valores e aspirações no que se refere à ordem internacional;

b) A orientação pragmática: o apoio brasileiro às posições norteamericanas no cenário global ou hemisférico deveria se dar em troca da cooperação ou ajuda dos Estados Unidos aos objetivos do Brasil.

c) E o critério de preponderância: as relações do Brasil com a América Latina permaneceriam subordinadas aos interesses compartilhados entre Brasil e Estados Unidos.

Certamente que nos anos posteriores, a atuação da Chancelaria brasileira não esteve circunscrita tão somente aos princípios do pan-americanismo. Os espaços mundiais eram bem amplos, e a Primeira Guerra Mundial apresentou novos cenários nos quais o Brasil passou a se movimentar e apresentar novas demandas. Isto pode ser percebido, por exemplo, pelas 
pretensões nacionais em fazer parte, já na década de 1920, do Conselho de Segurança da Liga das Nações. ${ }^{4}$

A década de 1930, contudo, teve uma dupla face: representou ao mesmo tempo o ápice e o declínio do modelo seguido pelo Barão do Rio Branco. A crise econômica internacional impôs limites, mas também abriu possibilidades para a política exterior brasileira (CORSI, 2000). A disputa entre alemães e norte-americanos levou ao enfraquecimento do componente ideológico nas relações entre Brasil e Estados Unidos. Em conseqüência disso, passou a prevalecer na política do Brasil o aspecto pragmático, ou seja, a tentativa de maximizar o seu poder de barganha explorando o interesse demonstrado no país por aquelas potências. ${ }^{5}$

Com o desdobramento da Segunda Guerra Mundial, o Brasil aproximou-se dos Estados Unidos, definitivamente a partir de 1942, estabeleceu uma aliança político-militar formal, e participou diretamente na Guerra, enviando para campos de Itália os febianos.

Esses compromissos entre Brasil e Estados Unidos durante o conflito, fizeram com que esse período do imediato pós-guerra fosse interpretado como um momento em que prevaleceram "relações especiais" entre ambos. $\mathrm{Na}$ realidade, o que se observou foi uma insistência mal sucedida do governo de Eurico Gaspar Dutra em busca de uma colaboração norte-americana mais efetiva para o desenvolvimento econômico. A reivindicação brasileira de "parceria privilegiada" com os Estados Unidos revelou-se frustrada devido aos compromissos que o governo de Washington, hegemônico depois de 1945, assumiu em termos globais com a reconstrução européia e com a disputa militar e ideológica contra o regime soviético (CERVO, 1994).

Nesse ínterim, os interesses latino-americanos de aprofundamento do regionalismo econômico foram relegados a um plano secundário, e subordinados às políticas de segurança regional (MALAN, 1986). O compromisso ideológico no relacionamento Brasil - Estados Unidos, que havia sido retomado no âmbito das "relações especiais" durante o governo Dutra, se 
desgastou, abrindo espaços para a vertente pragmática da atuação nacional.

Apenas com a Guerra da Coréia (1950-53) surgiram outras possibilidades de cooperação mais sólida dos Estados Unidos para a política de desenvolvimento dos países latinoamericanos. Assim, nos dois primeiros anos do governo Vargas foi possível aumentar o poder de barganha do Brasil. Tal quadro foi facilitado por várias razões: a primeira delas, pela solicitação norte-americana (não atendida) de envio de tropas brasileiras para o front coreano; a segunda, pelo fornecimento de minerais estratégicos, importante para os esforços militares; por último, a promessa de financiamento aos programas de desenvolvimento brasileiro e a criação da Comissão Mista Brasil - Estados Unidos para o Desenvolvimento Econômico. ${ }^{6}$

O sucesso inicial da estratégia brasileira de barganha foi resultado, em grande medida, da firme atuação dos países latino-americanos que se opuseram ao governo norte-americano no decorrer da IV Reunião de Consulta. Naquela ocasião o Brasil obteve condições entendidas como favoráveis nas negociações bilaterais com a Casa Branca.

\section{A Conferência de Washington (1951)}

A partir de junho de 1950, os Estados Unidos empenharamse em assegurar uma ativa cooperação econômica e militar com o Brasil, cujo sucesso seria um exemplo que outros países sulamericanos deveriam seguir. $\mathrm{O}$ apoio brasileiro traria não apenas um respaldo material - envio de tropas e fornecimento de matérias-primas - mas, sobretudo, imprimiria legitimidade às requisições dos Estados Unidos aos demais países do continente (HILTON, 1981).

Para o Brasil, atender as demandas norte-americanas significava a chance de barganhar o apoio político-militar em troca de ajuda técnica e dos aportes financeiros que 0 desenvolvimento econômico exigia (GV 51.01.04/2). 
A agenda da Conferência, aprovada em janeiro de 1951, elencava três itens para os trabalhos de consulta: 1) Cooperação política e militar para a defesa da América, 2) Segurança interna dos povos do hemisfério, e 3) Cooperação econômica de emergência (GV 51.03.16/1). A esses, trataria o Brasil de imprimir demandas próprias.

No que se refere ao primeiro item da agenda (cooperação política e militar), a linha de conduta da delegação brasileira consistiu em distinguir entre auxílio econômico para desenvolvimento do país e auxilio para a compra de equipamentos militares. Essa argumentação chocava-se com o entendimento norte-americano, que colocava o desenvolvimento e a preparação militar no mesmo nível de importância. Para o Brasil, ao contrário, a concessão financeira com objetivos militares deveria ser regida por regras mais brandas, próximas ao "lend and lease", ou pelo menos equiparadas ao auxílio dispensado às nações européias.

No item II (segurança interna do continente), a delegação brasileira defendeu o princípio da competência estritamente nacional para a execução de medidas de segurança interna. $\mathrm{Na}$ hipótese de haver indicação de resolução sobre possível internacionalização de atividades policiais repressivas, o Brasil manifestaria sua contrariedade. Nesse caso admitiria, entretanto, a possibilidade de coordenação entre os diferentes organismos policiais para a troca de informações e tomada de providências.

Quanto à cooperação econômica de emergência (item III), a orientação final foi de que o Brasil deveria sustentar uma postura na qual o auxílio dos Estados Unidos ao desenvolvimento econômico dos países não poderia sofrer qualquer prejuízo, em virtude da situação de emergência. O exemplo histórico utilizado para referendar dita instrução foi o da Segunda Guerra Mundial, cuja conseqüência fora o desgaste excessivo e danoso causado à economia brasileira. Ficara claro que os sacrifícios imputados às nações com menor capacidade eram proporcionalmente mais graves, e mais difíceis de serem reparados, do que aqueles impostos aos países industrializados. Amparada nessa 
perspectiva, a delegação brasileira pretendia defender "o princípio de que a cooperação de emergência, expressa em remessa de matérias-primas e outros produtos essenciais, tem de ser contrabalançada pelo apoio financeiro e pela garantia de suprimentos regulares à economia do Brasil" e dos países latinoamericanos. Representava, sobretudo, um projeto de resolução oferecido como um "corpo de doutrina sobre a cooperação continental". A essa doutrina ficariam ligadas as reivindicações em matéria de suprimentos de produtos necessários à vida econômica do país, de exportações brasileiras, de defesa do preço do café, de industrialização de combustíveis e de investimentos básicos para o desenvolvimento.

Definidos os parâmetros pelos quais a delegação brasileira orientaria suas decisões e os argumentos nos debates, o Ministro das Relações Exteriores João Neves da Fontoura, discursou em nome dos países latino-americanos (GV 51.03.16/1), em resposta ao pronunciamento de abertura do presidente Harry S. Truman (TRUMAN, 1951). Desde o início, os dois discursos expressaram o clima de desconfiança e divergência em que transcorreriam os trabalhos da Conferência. De um lado, os Estados Unidos mostraram-se preocupados com a ameaça comunista, e se esforçaram para sensibilizar a América Latina contra o perigo da subversão de origem interna. Por outro, os líderes desta parte do mundo procuraram relacionar o subdesenvolvimento à instabilidade política, buscando persuadir os Estados Unidos sobre a necessidade de um programa maciço de investimentos públicos em infra-estrutura e industrialização.

Embora o presidente norte-americano tentasse, em tom conciliador, frisar a importância e a centralidade da política de segurança global encabeçada pela ONU, e o papel coadjuvante porém não prescindível - que a América Latina representava dentro dele, o teor crítico e reivindicativo do discurso do chanceler brasileiro prevaleceu. Neves da Fontoura fez um balanço das economias latino-americanas, de suas deficientes "forças econômicas combalidas ou pelo menos debilitadas", com suas indústrias mal aparelhadas e os preços de suas produções 
agrícolas desvalorizados. Alertou ainda para o "flagelo da inflação do papel moeda", os orçamentos públicos deficitários e a carestia de vida. Segundo analogia do Ministro brasileiro, a situação dos países latino-americanos em relação aos outros desenvolvidos poderia ser comparada à de Pizarro, "que pedia comida aos incas, e estes lhe serviam apenas ouro, que não mata a fome". Se bem que um tanto extensa, vale a pena aqui transcrever parte de sua fala, quando argumentava:

"E a miséria é sempre, para os indivíduos como para os povos, a pior das conselheiras. Quando de novo a ameaça de terceiro conflito bate às nossas portas, e a emergência da guerra se fixa no quadro da atualidade, somos levados a corrigir esses erros da última década. (...) Estamos, de nossa parte, todos prontos a participar de uma quota na escala dos sacrifícios, mas não poderemos reincidir nas práticas do passado sem que esse nosso sacrifício constitua a ruína para nós, sem nenhuma vantagem para o mundo. Precisamos, assim, encontrar aqui a fórmula de cooperação econômica recíproca, não apenas de emergência e que nos prepare o futuro da indispensável recuperação e que, estimulando com os auxílios técnicos e financeiros o surto de nossa industrialização, aumente o nível de vida dos habitantes das diversas regiões do Continente, criando-se uma atmosfera de trabalho e de bem-estar para todos. No mundo dos nossos dias, não só os indivíduos como os povos devem gozar de iguais oportunidades; inclusive porque a interdependência das nações é tão estreita que a miséria de algumas terá inevitáveis e perigosos reflexos sobre as outras".

O pronunciamento do embaixador João Neves da Fontoura assumiu uma clara linha de argumentação contrária ao anseio de Washington, embora procurasse harmonizá-lo "com os deveres de cortesia de quem fala em casa alheia". Tal preocupação advinha do esperado impacto e repercussão sobre o posicionamento do Brasil durante e após a IV Reunião. De fato, as clivagens que se estabeleceram desde a sessão inaugural entre a postura do Brasil e a dos Estados Unidos, no campo econômico fundamentalmente, marcaram não só os trabalhos da 
Reunião de Consulta, mas também as negociações bilaterais que paralelamente se realizaram.

Os jornais norte-americanos que fizeram a cobertura dos trabalhos, principalmente o The New York Times e o The Washington Post, expressaram de forma oportuna as divergências de interesses e de pontos de vista entre o anfitrião e os participantes latino-americanos. Em relação aos discursos inaugurais, The Washington Post anotou um tópico importante, motivo de preocupação dos Estados presentes, ou seja, na área econômica. Lembrava que, no esforço conjugado de defesa, os países poderiam ser levados a uma expansão econômica artificial, resultando daí uma contração com inevitável impacto inflacionário. Chamava a atenção, ainda, para a necessidade de que a América não fosse lembrada somente em momentos de crise. Pelo contrário, deveriam os Estados Unidos considerar "em tom realista, seguras práticas de estabilidade, como contratos a longo prazo, para os materiais de que necessitamos [Estados Unidos]". Acima de tudo, essa avaliação era um sinal de que a imprensa apreendeu os anseios das nações latinoamericanas de construir uma base mais sólida, mais objetiva e menos lírica das "nossas relações tradicionais com os Estados Unidos da América" (GV 51.03.16/1, CT-2, 1973). ${ }^{7}$

$\mathrm{Na}$ contramão da boa acolhida do discurso do ministro brasileiro, o pronunciamento do presidente Truman não recebeu destaque na edição do mesmo periódico, por causa das declarações improvisadas acerca da construção de um canal no Peru que tornasse viável o acesso ao mar para a Bolívia, saída essa perdida na Guerra do Pacifico em 1879. Como tal fato não havia se concretizado, sob qualquer aspecto, as declarações de Truman poderiam ser "eventualmente utilizadas em futuras campanhas políticas na América Latina" (GV 51.03.16/1, CT-19, 2007).

Dentre as discussões que despontaram nos trabalhos de consulta, uma particularmente assumiu proeminência, por ser representativa das divergências travadas no campo econômico entre latino-americanos e norte-americanos. Em um dos debates acerca do desenvolvimento econômico, os Estados Unidos 
defenderam vigorosamente a premissa de que a "atual" situação de emergência deveria prevalecer sobre os programas de desenvolvimento econômico. Sob tal ótica, esses não constituíam condição única para se evitar que o comunismo se propagasse nos países "sub-desenvolvidos". Deveriam juntar-se a eles, reformas agrárias, revogação de leis que impedissem a produção, etc. Em seguida, o delegado norte-americano reportou-se aos sacrifícios de 250 mil famílias americanas cujos filhos se encontravam mobilizados, e qualificou de "comerciais" as proposições latino-americanas sobre desenvolvimento econômico. Como resposta, Colômbia e Cuba reagiram com indignação, empregando energia raramente observada em foros pan-americanos. Por causa das fortes pressões, o representante norte-americano desculpou-se e atribuiu o mal-entendido à dificuldade em se expressar em língua espanhola. $O$ delegado brasileiro, Euvaldo Lodi, procurou conciliar os desentendimentos, não deixando, porém, de estranhar a qualificação dada ao documento, que incluía vários dispositivos do projeto brasileiro. Por conseguinte, a delegação dos Estados Unidos transigiu em alguns pontos de importância, permitindo a conclusão desse projeto sobre desenvolvimento econômico. (GV 51.03.16/1, CT-30, 2133).

$\mathrm{Na}$ avaliação de Neves da Fontoura, a reação da imprensa e da administração norte-americana seria um elemento favorável quando se intensificassem as negociações bilaterais que interessavam ao Brasil. E acrescentava: "Apesar do inevitável choque de pontos de vista, nunca foram tão promissoras as relações Brasil - Estados Unidos" (GV 51.03.16/1, CT-33, 2144).

Do ponto de vista político, a Conferência de Washington expressou a "unidade de vistas" entre as Repúblicas do hemisfério, dando ao mundo exemplo de "solidez e homogeneidade do bloco continental" (MRE, 1951; VARGAS, 1954). Símbolo máximo dessa convergência de diretrizes e princípios políticos foi a resolução denominada "Declaração de Washington", que, embora não tivesse um caráter propositivo, serviu para reafirmar a "determinación de las Repúblicas Americanas de mantenerse inquebrantablemente unidas, en lo 
espiritual y en lo material, en la actual situación de emergencia o ante toda agresión o amenaza contra cualquiera de ellas". Reiterou-se também "la fe (...) en la eficácia de los princípios establecidos en la Carta de la Organización de los Estados Americanos" para se preservar a paz e a segurança hemisféricas, bem como "mejorar las condiciones de vida de sus pueblos, propender a su desarrollo cultural y económico y asegurar el respeto a las libertades fundamentales del Hombre y a los principios de justicia social como bases de un sistema democrático" (WASHINGTON, 1951).

Com essa mesma unidade de princípios, outra resolução reafirmou o "apoio das Repúblicas americanas à ação das Nações Unidas para reprimir a agressão soviética na Coréia e em qualquer outro ponto onde ela se manifeste" (MRE, 1951). Para tanto, recomendava-se que cada uma das nações signatárias procedesse ao estudo imediato de seus recursos, especificando "las medidas que puedan adoptar para contribuir a la defensa del continente y al esfuerzo de las Naciones Unidas", dentro da resolução "união pela paz" da Assembléia Geral.

Quanto à cooperação militar interamericana, a Reunião de Consulta resolveu recomendar às Repúblicas Americanas "que orientem su preparación militar de tal manera que (...) puedan, sin prejuicio de la legitima defensa individual y de la seguridad interna", aumentar seus recursos e reforçar suas Forças Armadas de modo a atenderem prontamente à defesa do continente e à repressão de eventual agressão contra qualquer uma delas. Em caráter complementar, a resolução encarregou ainda à Junta Interamericana de Defesa (JID) a responsabilidade pelo planejamento militar para a defesa comum, sujeito à aprovação dos diferentes governos e envolvendo todas as tarefas militares sob a chancela de cada um dos países. Conforme Relatório Ministerial de 1951, tal plano foi elaborado pela JID, na forma de decisão referida, sendo aprovado e comunicado aos diferentes governos em novembro daquele ano.

No plano econômico observaram-se inicialmente divergências de interpretação dos problemas entre os governos do hemisfério, que depois convergiram para o êxito das decisões 
finais. Os Estados Unidos, empenhados em um grande plano de mobilização econômica para a defesa, procuraram distribuir o ônus da segurança coletiva para todo o hemisfério. Em tal projeto estavam previstas a mobilização de recursos do continente, suprimentos de matérias-primas e manufaturas, além de diversas limitações às atividades econômicas com objetivos civis. Os países latino-americanos, por sua vez, defenderam os argumentos da delegação brasileira de que

“(...) os problemas suscetíveis de serem relegados a um período de normalidade internacional eram partes integrantes da economia de emergência, tanto pela necessidade de defender aquelas estruturas sociais e econômicas dos desgastes e distorções do período de anormalidade, quanto pela imperiosa necessidade de aparelhá-la para contribuírem regularmente no esforço comum". (MRE, 1951: 14).

Diante da reiterada persistência das delegações latinoamericanas sobre essa compreensão dos fatos, a ata final da Reunião de Consulta declarou, na Resolução XII, entre outros pontos importantes, "que el desarrollo económico de los países insuficientemente desarrollados se considera como elemento esencial dentro del concepto total de la defensa del Hemisferio". A ata deixava igualmente claro, que não se poderia desconhecer que seria dever dos Estados americanos fortalecerem suas defesas e manterem as atividades civis essenciais.

Desse princípio, ainda no campo econômico, decorreriam as normas específicas destinadas a assegurar o aumento da produção e a transformação de materiais básicos e estratégicos; a produção e utilização de produtos essenciais escassos; a defesa econômica e controles de segurança; as quotas e prioridades; o controle justo e racional dos preços; a manutenção dos transportes; a liquidação dos estoques de emergência; e os planos de desenvolvimento econômico, visando modernizar a agricultura, aumentar a produção de alimentos, desenvolver os recursos minerais e de energia hidroelétrica, intensificar a industrialização, melhorar os meios de transporte, elevar os 
níveis de saúde e educação, estimular a inversão de capitais particulares e públicos, estimular o emprego e elevar a capacidade diretiva e perícia técnica conexa, e melhorar as condições de vida das classes trabalhadoras.

Embora a leitura dos documentos oficiais sobre a IV Reunião de Consulta induza-nos a crer na estratégia de separação entre os aspectos políticos e econômicos da Conferência - aquele apresentado enquanto princípio consolidado e indeclinável e este como elemento de negociação -, o acompanhamento pari passu dos trabalhos das comissões e subcomissões, incumbidas das discussões dos projetos de resolução, elimina aquela impressão. As nações do continente aceitaram, incondicionalmente, o princípio da defesa dos valores democráticos e suas implicações quanto à segurança interna e coletiva, mas o mesmo não pode ser dito sobre a aprovação da tática de sua consecução. A definição desse elemento tático, por sua vez, apresentou-se como uma decisão política, por causa dos debates travados no seio da Conferência e nos bastidores, para a aprovação da proposição axiomática encabeçada pela delegação brasileira e seguida pelos demais países latino-americanos. Isto porque

“(...) urgia dizer, com cortesia, mas com firmeza, ao Presidente dos Estados Unidos e à Nação Americana, que não voltaríamos a incidir no mesmo erro. Por cooperação só e só de emergência não teria nosso apoio. A única forma que compreendíamos de cooperar, para eventualidade de guerra, era a de cooperarmos todos também para o desenvolvimento econômico de cada um dos nossos países. E por quê? Porque se tratava precisamente de combater o comunismo." (EXPOSIÇÃO..., 1951: 34).

Conforme interpretação desse fato, "a articulação entre a cooperação político-militar e econômica era percebida como uma estratégia exitosa" pela delegação brasileira (HIRST, 1996: 213). No entanto, o otimismo quanto aos resultados daquela opção estava ligado às conquistas advindas das negociações bilaterais 
O BRASIL E A CONFERÊNCIA DE WASHINGTON (1951)...

brasileiro-norteamericanas e às perspectivas de relações cooperativas subseqüentes.

O Brasil, nesse sentido, privilegiou as conversações diretas com os Estados Unidos em detrimento das conquistas multilaterais, ou seja, aquelas que beneficiassem o conjunto dos países latino-americanos. Como resultado dessa forma de atuação, a delegação brasileira alcançou nos bastidores os seguintes resultados: 1) constituição de uma Comissão Mista, integrada por americanos e brasileiros, e fortemente prestigiada pelo Departamento de Estado, para estudar os planos básicos de desenvolvimento brasileiro, fornecendo a cooperação técnica e financeira dos Estados Unidos; 2) auxílio de US\$300 milhões de dólares pelo BIRD para financiamento dos projetos aprovados pela Comissão; 3) representação permanente do Banco Internacional no Rio de Janeiro para acompanhar os projetos da Comissão; 4) auxílio do Banco sob a forma de financiamento para importações de bens inseridos à vista no mercado brasileiro, para a recuperação de cruzeiros a serem utilizados pelo governo nos planos de desenvolvimento; 5) contato permanente, na pessoa do Presidente da Comissão, Sr. Francis Truslow, com a repartição encarregada da concessão de prioridades aos planos de desenvolvimento; 6) concessão de vinte bolsas especiais da Divisão de Assistência Técnica das Nações Unidas para treinamento de economistas e técnicos brasileiros; e 7) criação de um grupo americano-brasileiro encarregado de estudar as quotas de suprimentos essenciais para a manutenção da economia brasileira, diante do racionamento para a situação de emergência (GV 51.03.16/1).

Não resta dúvida de que o aspecto realista prevaleceu no posicionamento brasileiro. Apoiado e seguido pelos demais países latino-americanos, o Brasil opôs-se à atuação dos Estados Unidos que, no período pós-guerra, relegou a um plano secundário não apenas os países da região, como também os da Ásia e da África. Embora fosse patente a prioridade atribuída pelos Estados Unidos à defesa militar, decorrendo daí a proposta de que fossem aplicados ao desenvolvimento econômico os recursos restantes da ajuda militar, a posição vencedora 
estabelecia que o plano de defesa não deveria prejudicar o plano econômico. $\mathrm{O}$ argumento de que o desenvolvimento econômico era fator primordial no combate interno dos países ao comunismo foi utilizado igualmente tanto para pressionar os Estados Unidos, quanto como forma de denotar convergência de princípios com o bloco capitalista, afastando-se das influências do leste europeu.

No plano multilateral, o Brasil rejeitou uma postura de alinhamento automático, de transigência ilimitada com os Estados Unidos, em troca de um possível tratamento favorável bilateral. Apostou, ao contrário, em uma resistência moderada, justificada sempre do ponto de vista técnico e econômico, e que lhe garantiu prestígio para as negociações bilaterais.

O reflexo imediato do dissídio de posturas entre os países latino-americanos e o governo de Washington foi a alteração da política econômica norte-americana para o continente. Do ponto de vista dos interesses brasileiros, houve a criação da Comissão Mista Brasil - Estado Unidos para o Desenvolvimento Econômico e o Acordo Militar Brasil - Estados Unidos, que podem ser creditados como desdobramentos diretos das negociações bilaterais e do comportamento independente e pragmático da política externa brasileira naquela oportunidade.

\section{Considerações finais: o legado diplomático da Conferência de Washington}

Se bem que a IV Reunião de Consulta dos Chanceleres Americanos não esgotasse as ocasiões em que se veria uma diferença de posturas entre países latino-americanos e o governo norte-americano, ela representou a primeira chance no pós-guerra em que as divergências entre esses agentes foram expressas formalmente em um foro multilateral, tendo contado com o apoio da maioria dos países do continente.

Até aquele momento, os encontros interamericanos do pósguerra tinham servido apenas para referendar a estrutura do poder político e econômico norte-americano. Na Conferência 
Interamericana para Manutenção da Paz e da Segurança no Continente, de 1947, criou-se o Tratado Interamericano de Assistência Recíproca (TIAR), acordo militar pelo qual os países latino-americanos se comprometiam a apoiar qualquer um dos signatários em caso de ameaça externa. Na IX Conferência Interamericana de 1948 o advento da Organização dos Estados Americanos institucionalizou a prática pan-americana desenvolvida desde a Doutrina Monroe, permitindo em parte que os Estados Unidos mantivessem sob controle a política interna dos países do hemisfério (MOURA, 1996).

A Conferência de Washington se apresentou como expressão, ainda que rudimentar, de uma postura de distanciamento que gradativamente se verificava nas relações internacionais entre economias periféricas e as potências mundiais durante a Guerra Fria. Nesse sentido, aproximava-se das posições assumidas no contexto da descolonização afroasiática, apresentando uma dinâmica muito semelhante àquela que seria vista na Conferência de Bandung, em abril de 1955. Tanto a Conferência de Washington quanto a de Bandung representaram o prenúncio de uma nova conceituação dos problemas internos e externos dos países periféricos, baseada nas necessidades de desenvolvimento e de satisfação dos reclamos de uma opinião pública, bastante cética quanto às ajudas e propostas que ficavam restritas ao mero plano retórico.

No caso da política externa brasileira, a atuação nacional na IV Reunião de Consulta pode ser entendida como a primeira manifestação de um padrão diplomático assentado na multilateralização e na barganha nacionalista com os Estados Unidos. Posteriormente tal modus operandi ganharia contornos diversos e se consolidaria, mesmo que de forma parcial, nos governos de Juscelino Kubitschek, Jânio Quadros e João Goulart (VIZENTINI, 2004).

De certa forma, o vínculo entre subdesenvolvimento e instabilidade política, entre problemas econômicos e políticos, esteve presente em outros momentos quando os interesses da América Latina se diferenciavam dos propósitos dos Estados Unidos, por exemplo na Operação Pan-Americana de Juscelino 
Kubitschek de Oliveira, e na Política Externa Independente de Jânio da Silva Quadros e de João Belchior Marques Goulart (BUENO, 2000).

Nesse sentido, o governo brasileiro, ao reformular sua política exterior colocou-se em consonância com as necessidades apresentadas pelo desenvolvimento nacional. Não apenas isso, mas também expressou a opinião de parte da sociedade que, ao longo do tempo, se conscientizou das condições em que se encontrava o país, cujos interesses nem sempre coincidiam com os das superpotências, mas que aproximava o Brasil de outras nações que padeciam de males semelhantes.

Essa nova dinâmica das políticas interna e externa brasileiras, aliada a um esvaziamento da ênfase nas "relações especiais" Brasil - Estados Unidos, levou o país também à procura de uma aproximação maior com os vizinhos sulamericanos, e que pode ser observado através de propostas de integração regional, como o Pacto $\mathrm{ABC}$ e a ALALC.

A postura realista da diplomacia brasileira e o progressivo afastamento dos Estados Unidos no período pós-guerra, teriam como desdobramento a construção de uma política externa baseada na perseguição de uma autonomia maior, visando a inserção internacional mais favorável para o país, tendo como um dos grandes parceiros o bloco do Terceiro Mundo.

\section{Referências Bibliográficas}

BUENO, C. -Política externa da Primeira República: os anos de apogeu de 1902 a 1918. São Paulo: Paz e Terra, 2003, 506p.

. Relações Brasil - Estados Unidos (1945-1964). In: ALBUQUERQUE, J. A. G. (Org.). Sessenta anos de política externa brasileira (1930-1990): o desafio geoestratégico. Vol. III. São Paulo: Annablume/NUPRI/USP, 2000, $500 \mathrm{p}$.

CPDOC/FGV. - Centro de Pesquisa e Documentação de História Contemporânea do Brasil. Fundação Getúlio Vargas. 
CERVO, A. L. -Relações Internacionais do Brasil. In: CERVO, A. L. (Org.) O Desafio Internacional: a política exterior do Brasil de 1930 a nossos dias. Brasília: Unb, 1994.

CORSI, F. L. -Estado Novo: política externa e projeto nacional. São Paulo: Editora da Unesp, 2000, 305 p.

EXPOSIÇÃO do Ministro João Neves da Fontoura aos membros das Comissões de Relações Exteriores do Senado Federal e de Diplomacia e Tratado da Câmara dos Deputados e aos Líderes dos Partidos Nacionais com Assento no Parlamento, em 29 de maio de 1951. Serviço de Publicações. Ministério das Relações Exteriores, 1951.

GAMBINI, R. -O duplo jogo de Getúlio Vargas. São Paulo: Edições Símbolo, 1977. 175p.

GARCIA, E.V. -O Brasil e a Liga das Nações (1919-1926). Porto Alegre/Brasília: Editora da Universidade Federal do Rio Grande do Sul/Fundação Alexandre de Gusmão, 2000, 168p.

. Entre América e Europa: a política externa brasileira na década de 1920. Brasília: Editora UnB/Fundação Alexandre de Gusmão, 2006. 671p.

GV - Arquivo Getúlio Vargas - CPDOC/FGV.

HILTON, S. E. -The United States, Brazil, and the Cold War, 1945-1960: End of the Special Relationship. The Journal of American History, v.68, n.3, 1981.

HIRST, M. -A política externa do segundo governo Vargas. In: ALBUQUERQUE, J. A. G. (Org.). Sessenta anos de política externa brasileira (1930-1990): crescimento, modernização e política externa. Vol. I. São Paulo: Edusp, 1996, 388p.

MALAN, P. S. -Relações econômicas internacionais do Brasil (19461964). In: FAUSTO, B. (Org.). História Geral da Civilização Brasileira. 2.a ed. Vol. IV. São Paulo: Difel, 1986.

MOURA, G. A.- Segurança Coletiva continental: o sistema interamericano, o TIAR e a Guerra Fria. In: ALBUQUERQUE, J. A. G. (Org.). Sessenta anos de política externa brasileira (1930-1990): crescimento, modernização e política externa. Vol. I. São Paulo: Edusp, 1996, 388p.

- -Autonomia na dependência: a política externa brasileira de 1935 a 1942. Rio de Janeiro. Nova Fronteira. 1980, 194p.

MRE. Relatório do Ministério das Relações Exteriores. Rio de Janeiro, Serviços de Publicações da Divisão de Documentação, 1951.

RICUPERO, R. -O Brasil, a América Latina e os EUA desde 1930: 60 anos de uma relação triangular. In: ALBUQUERQUE, J. A. G. (Org.). 
Sessenta anos de política externa brasileira (1930-1990): crescimento, modernização e política externa. São Paulo: Cultura Editores, 1996.

SEITENFUS, R. A. S. O Brasil de Getúlio Vargas e a formação dos blocos (1930-1942). São Paulo: Companhia Editora Nacional, 1985, 488p.

TOCQUEVILlE, A. De. - A democracia na América. 2.a ed. Belo Horizonte/São Paulo: Editora Itatiaia/Editora da Universidade de São Paulo, 1977, 620p.

TRUMAN, H. -Address Opening the Meeting of the Foreign Ministers of the American Republics. Disponível em < http://www.trumanlibrary.org/>. Acesso em 10/10/2008.

VARGAS, G. -O Governo Trabalhista no Brasil. Vol. II. Rio de Janeiro: José Olympio, 1954.

VIZENTINI, P. F. Relações Exteriores do Brasil (1945-1964): o nacionalismo e a política externa independente. Petrópolis/RJ: Vozes, 2004, 279p.

WASHINGTON. Acta Final. Unión Panamericana. Cuarta Reunión de Consulta de Ministros de Relaciones Exteriores. División de Conferencias y Organismos. Departamento Jurídico y de Organismos Internacionales, 1951. Disponível em www.oas.org. Acesso em $04 / 12 / 2008$.

DALIO, Danilo José; MIYAMOTO, Shiguenoli. The Conference in Washington (1951) and the historical roots of a new standard Brazilian diplomatic. História, v.28, n.2, p.57-78, 2009.

\begin{abstract}
The 1940s represented the peak and decline of the paradigm of the "special relationship" Brazil - United States, predominant for almost half a century in the Brazilian foreign policy. After the successful experience of collaboration during the Second World War, Brazil faced a period of frustration and disappointment in their relations with the government in Washington. Emerging as a hegemonic power, successive Americans governments have global interests and objectives in the new international order, leaving little to meet the demands of Latin American countries. The Fourth Meeting of Consultation of Foreign Ministers American held in Washington, between March and April 1951, explicited not only the goals and interests of disagreement between the U.S. and Latin American countries in the post-war, but also the emergence of a new perspective on
\end{abstract}


O BRASIL E A CONFERÊNCIA DE WASHINGTON (1951)...

relations within the continent, namely, from that time based on realistic and pragmatic negotiations, this orientation led by Brazil during the meeting.

Keywords: Conference in Washington; Brazil-United States Relations; Brazilian Foreign Policy; Latin America.

\section{NOTAS}

${ }^{1}$ Não vamos aqui arrolar esses eventos por todos conhecidos. Alguns fatos, desde o final da Guerra, com fortes atuações dos Estados Unidos e do Reino Unido podem aqui ser lembrados: o discurso de Winston Churchill em Fulton em 1946 denunciando o surgimento da "cortina de ferro", o pronunciamento de Harry Truman, em 1947, sobre a necessidade de todos se posicionarem a favor de um dos dois blocos, e o artigo publicado também em 1947 na revista Foreign Affairs por George Kennan, sob o pseudônimo de "Mr. X".

${ }^{2}$ Quase um século antes, na década de 1830, Aléxis de TOCQUEVILLE (1977: 314-315), já se referia ao futuro papel a ser desempenhado pelos anglo-americanos e pela Rússia dos Czares: "Existem hoje, sobre a terra, dois grandes povos que, tendo partido de pontos diferentes, parecem adiantar-se para o mesmo fim: são os russos e os angloamericanos (...) O seu ponto de partida é diferente, os seus caminhos são diversos: não obstante, cada um deles parece convocado, por um desígnio secreto da Providência, a deter nas mãos, um dia, os destinos da metade do mundo".

${ }^{3}$ É importante notar que os interesses do Brasil no início do século XX estiveram ligados, sobretudo, à solução das disputas e interesses fronteiriços.

${ }^{4}$ A política externa dos anos 1920 mereceu ampla reflexão de Eugênio Vargas Garcia em duas importantes obras: na primeira explora a demanda feita pelo Brasil na Liga das Nações, mostrando que a pretensão brasileira em instituições desse porte já é bastante antiga; na segunda analisa a ampliação do raio de atuação da PEB, abarcando a Europa e a América (GARCIA, 2000 e 2006).

${ }^{5}$ Esse fato já foi explorado em interessantes textos, por exemplo, de GAMBINI (1977), que mostra as ambigüidades do governo brasileiro, oscilando entre os dois países, em busca de recursos, enquanto 
SEINTENFUS (1985) realizou extensa obra sobre a participação do Brasil na Segunda Guerra Mundial. Os livros de MOURA (p.e.1996) são referências importantes sobre esse período da história brasileira.

${ }^{6}$ Não é aqui nosso objetivo explorar a política doméstica ou as orientações econômicas que prevaleceram no período analisado. Além do mais, é extensa e conhecida a bibliografia que trata dos aspectos políticos e econômicos nacionais dos anos 50. Basta aqui remetermos a consulta a autores como Celso Lafer, Maria Victoria Benevides, Sonia Draibe, Betty Mindlin Lafer, Miriam Limoeiro, Maria do Carmo Campello de Souza, entre dezenas de outros, que dão conta de aspectos variados do quadro da política brasileira.

7 À numeração da documentação diplomática (Ex: GV 51.03.16/1), presente no Arquivo Getúlio Vargas (GV) do Centro de Pesquisa e Documentação de História Contemporânea do Brasil (CPDOC), da Fundação Getúlio Vargas, segue-se a descrição própria do corpo do documento (Ex: CT-19, 2007).

Artigo recebido em 03/2009. Aprovado em 08/2009. 